D $D$

D

\title{
Implementation of educational projects in college studies
}

Zita Malciene ${ }^{a}$,

Laima Unterhauser ${ }^{b}$,

Suggested Citation:
D D

Abstract 
1. Introduction

D

D

2. Methods 
3. Results

D

Table 1. Students' attitude towards the importance of the educational project while training the future art specialist

D H 
Table 3. Importance of the educational project in developing students' personal characteristics D

$\mathrm{D}$

D 
4. Discussion

$\mathrm{H}$

5. Conclusions 
References

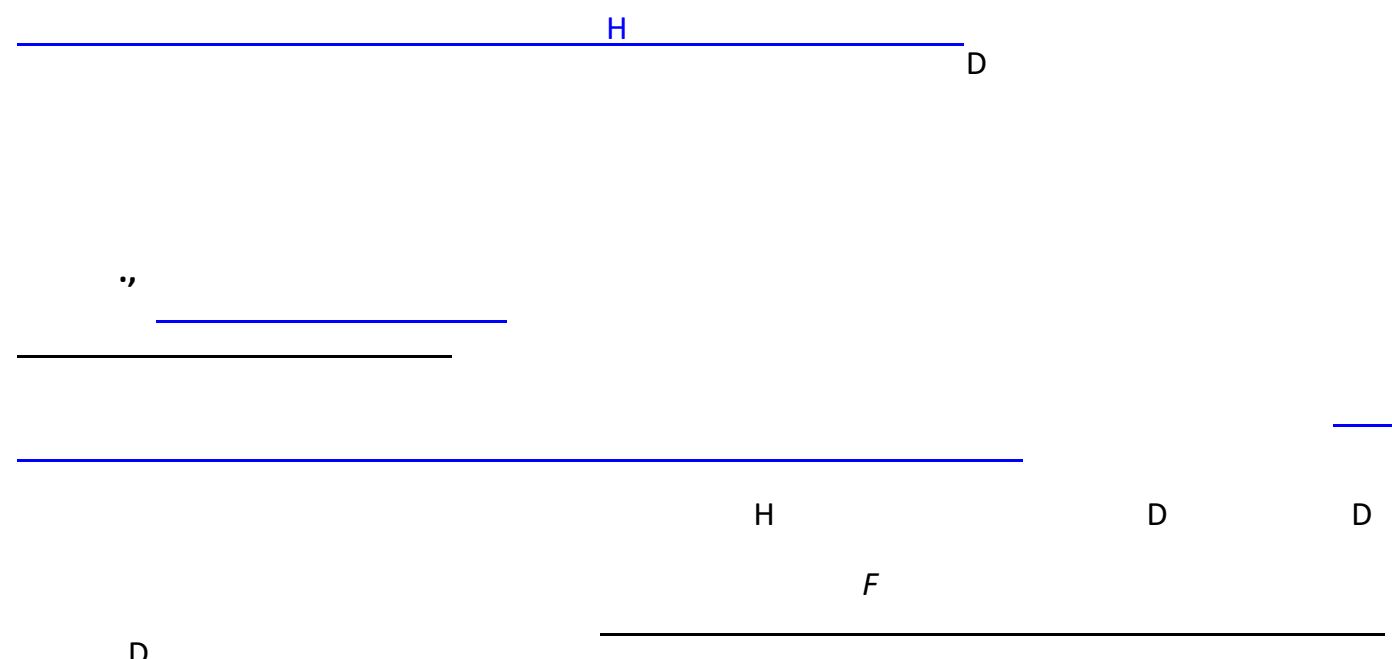

D

D 